\title{
Viral Infections
}

\author{
Ryan F. Relich
}

Despite major advances in basic and applied research and the availability of several vaccines, viral diseases still account for a large proportion of the human infectious disease burden. Many viruses cause self-limiting and relatively mild infections, but several, including human immunodeficiency virus and influenza virus, are responsible for millions of deaths every year throughout the world. Several factors contribute to the enormous impact that viruses have on human health. For example, there are very few therapeutic options available for the treatment of viral infections, and many of those that are available possess a limited spectrum of activity or are designed for the treatment of diseases caused by specific viruses (e.g., oseltamivir is intended for the treatment of influenza only). In addition, the rapid evolution of viruses has led to the emergence of drug-resistant strains against which no currently available therapeutics are effective. Coupled with these and other issues are the appearance of never before seen viruses and the emergence of known but previously underappreciated viruses. Since the beginning of the twenty-first century, numerous "new" viruses, including the coronaviruses responsible for severe acute respiratory syndrome (SARS) and Middle East respiratory syndrome (MERS), the 2009 pandemic influenza A virus, and Lujo hemorrhagic fever virus, have made their debut and have proved to be formidable threats to human health. Recently, the appearance of Ebola (Zaire ebolavirus) virus in West Africa, a region that has not previously seen an outbreak of this virus, was marked by an epidemic that afflicted nearly 30,000 individuals and killed more than 11,000 of those who were infected. Most recently, the far-reaching and rapid spread of Zika virus, a mosquito-borne virus that was discovered in the 1940s in Uganda, in the Western Hemisphere has invoked considerable public and scientific attention and has given rise to perhaps the largest concerted effort by scientists to rapidly develop a vaccine to halt the

\footnotetext{
R.F. Relich $(\bowtie)$

Department of Pathology and Laboratory Medicine, Indiana University School of Medicine, Indianapolis, IN, USA

e-mail: rrelich@iupui.edu
} 
transmission of a virus. Each of these points underscores the importance of further research into improved surveillance, diagnosis, treatment, and prevention of viral diseases.

The diagnosis of viral infections has traditionally relied upon the observation of clinical signs and symptoms alone or in conjunction with analysis of clinical specimens. Historical laboratory methods, including direct analysis of clinical specimens by transmission electron microscopy, immunofluorescence, and inoculation of cultured cells for recovery of infectious viruses have largely been supplanted by rapid immunoserologic and molecular methods that provide definitive answers in as little as a few hours or less. Despite their waning presence in clinical laboratories, these historical methods remain important for the detection and characterization of rare or new viruses and for basic virology research, among other things. The microscopic examination of fixed and paraffin-embedded tissue and fixed cell concentrates also plays an important role in the diagnosis of many viral infections. The recognition of virus infection-associated tissue architectural and cytologic changes (cytopathic effects) and the judicious use of immunohistochemical methods afford anatomic pathologists the ability to provide clinically meaningful information to healthcare providers regarding the type and extent of a viral infection. Chief among the requirements for optimal visualization of virusinduced histopathology and cytopathology is the procurement of high-quality clinical specimens, such as tissue biopsy specimens and body fluids. Sections of tissue destined for histopathologic examination should immediately be placed into an appropriate fixative (e.g., 10\% buffered formalin) and allowed to thoroughly fix prior to processing, staining, and examination. Specimens for other viral diagnostic studies, including viral cultures, may not be possible using formalin-fixed specimens; therefore separate sections of tissue should be submitted in transport media appropriate for the desired test(s). The same general considerations should be given when bodily fluids or exfoliated cell preparations are harvested for cytopathologic analysis.

In this chapter, representative photomicrographs of histopathologic and cytopathologic features of several viral infections are presented with brief descriptions of the viruses that cause them. Viral infections with readily detectable and distinguishing features that are likely to be encountered by anatomic pathologists in routine private and academic settings are presented along with a few examples of uncommonly encountered viral diseases.

\subsection{Viral Classification and Genomics}

Viruses are most commonly grouped by the type of nucleic acid, either DNA or RNA, that comprises their genomes and by the means by which their genomes are transcribed into messenger RNA. So far, seven distinct viral genome types are known and, to date, all characterized viruses possess one of these seven types. DNA genomes can exist either as double-stranded (dsDNA), gapped-double-stranded (g-dsDNA), or as single-stranded molecules (ssDNA). RNA genomes can also be 
double-stranded (dsRNA) or single-stranded (ssRNA). ssRNA genomes are further divided into three distinct types, including negative-sense ssRNA (-ssRNA), positive-sense ssRNA (+ssRNA), and positive-sense ssRNA that is reverse transcribed into a DNA intermediate (+ssRNA-RT). This generalized system for categorization of viruses is the backbone of the most widely used grouping system for viruses, the Baltimore classification system.

Viruses are also formally categorized according to conventional Linnaean taxonomic classification into orders, families, subfamilies, genera, and species. As of this writing and according to the latest virus taxonomy release of the International Committee on Taxonomy of Viruses, there are seven accepted orders, 122 families (of which 84 are not assigned to an order), 35 subfamilies, and many genera and species. Most of these viruses are not human pathogens, however. Examples of human viruses categorized according to genome type and formal taxonomic naming are listed in Table 3.1. For the most up-to-date information regarding viral systematics, please refer to the viral taxonomy listing of the International Committee on Taxonomy of Viruses (https://talk.ictvonline.org/taxonomy/).

\subsection{Human Adenoviruses}

In immunocompetent hosts, human adenoviruses (HAdVs) are common causes of usually self-limited respiratory tract and extrapulmonary infections, including coryza, conjunctivitis, and gastroenteritis; however, severe respiratory tract infections have been reported in otherwise healthy adults. Infections of immunosuppressed patients can lead to severe and sometimes fatal infections such as pneumonia, neurologic diseases, and diseases of the gastrointestinal and urinary tracts. Currently, there are $57 \mathrm{HAdV}$ types spanning seven species (Human mastadenovirus A-G) that belong to the genus Mastadenovirus. Like all members of the family Adenoviridae, HAdV possess monopartite, linear dsDNA genomes that are covalently linked to a terminal protein (TP) at the $5^{\prime}$-ends of both DNA strands. HAdV genomes measure approximately 36 kilobase pairs (kbp) in length and encode roughly 40 proteins. Once susceptible and permissive host cells are infected, viral replication and particle assembly occurs within the host cell nucleus (Figs. 3.1 and 3.2).

\subsection{Human Herpesviruses}

The family Herpesviridae is currently organized into three subfamilies, including Alphaherpesvirinae, Betaherpesvirinae, and Gammaherpesvirinae, and a single unassigned genus. Scattered among these subfamilies are nine human herpesviruses (see Table 3.2). Although it is not considered a human herpesvirus, Macacine alphaherpesvirus 1 (herpes virus B or " $\mathrm{B}$ " virus) is a zoonotic agent that is associated with severe and often fatal central nervous system infections in human hosts that acquire the virus through bites from infected macacine nonhuman primates (e.g., rhesus macaques). Virions are enveloped and contain an amorphous 


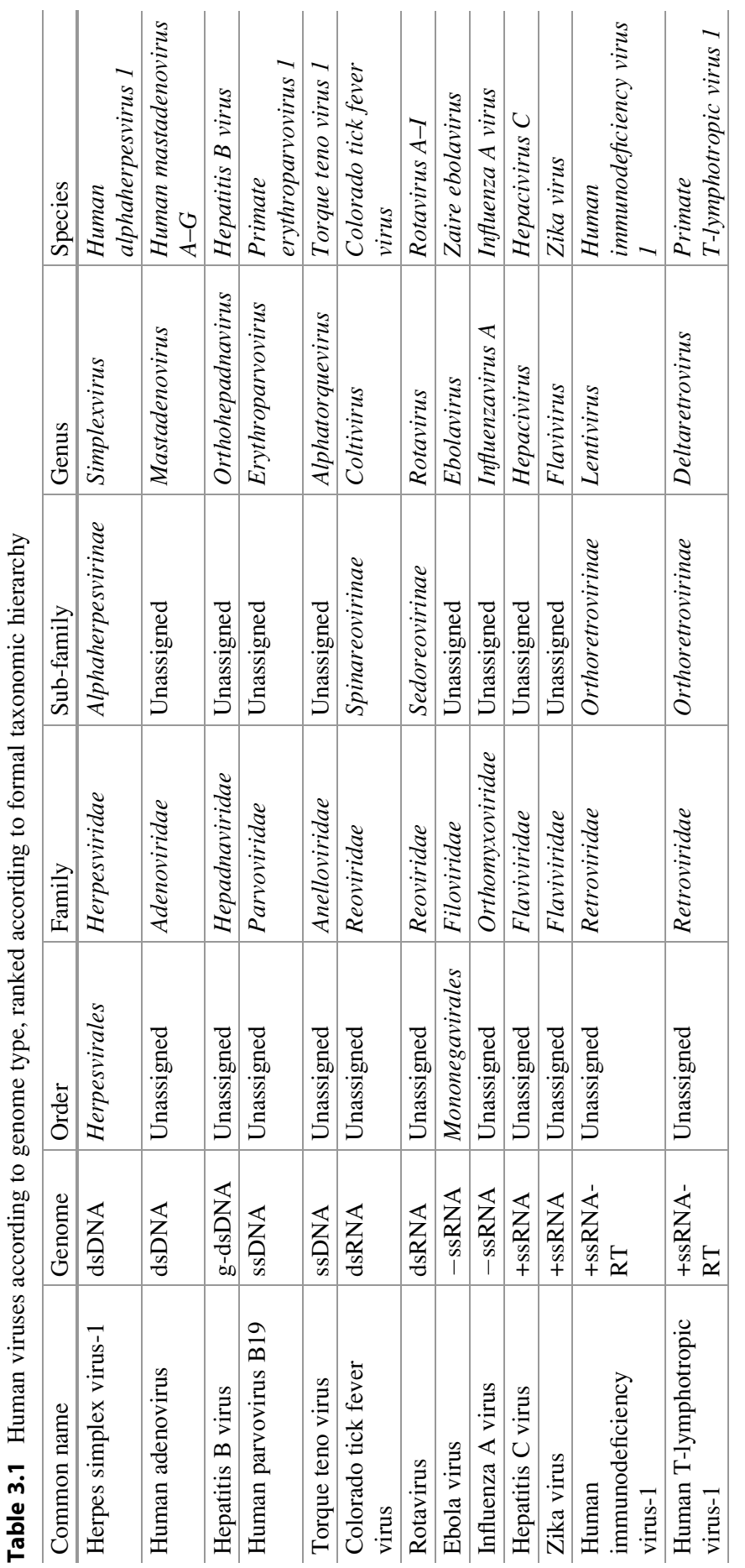




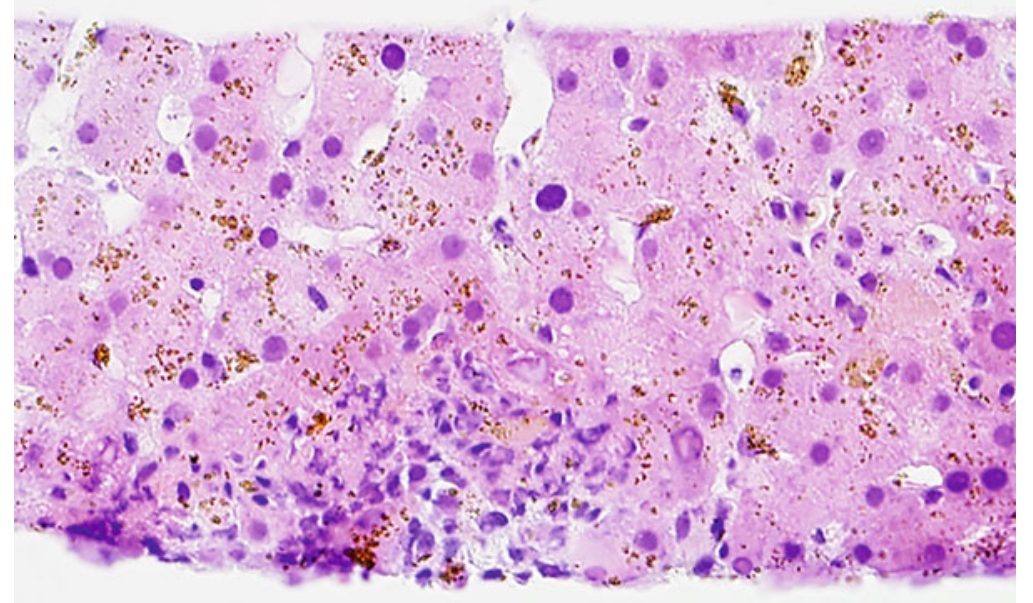

Fig. 3.1 Replication of adenoviruses results in cytopathic effects that are largely restricted to the nucleus, which is the site of adenoviral replication. Early in the viral infectious cycle, discrete eosinophilic inclusions composed of nascent particles are visible at relatively low magnifications. Continued assembly of new particles leads to expansion of these inclusions, which, over time, tend to stain more basophilic. In the terminal stages of progeny virus production, the nuclear membrane degenerates, imparting a blurred or smudged appearance to the nucleus. In the above image of an hematoxylin and eosin (H\&E)-stained liver core biopsy section, both early- and late-stage cytopathic effects are visible throughout the field. Bile crystals are also seen dispersed throughout the tissue, underscoring the importance of careful interpretation of observations, since pigment granules (e.g., bile, lipofuscin, anthracotic pigment) can sometimes be confused with nuclear and cytoplasmic viral inclusions. Original magnification, $400 \times$

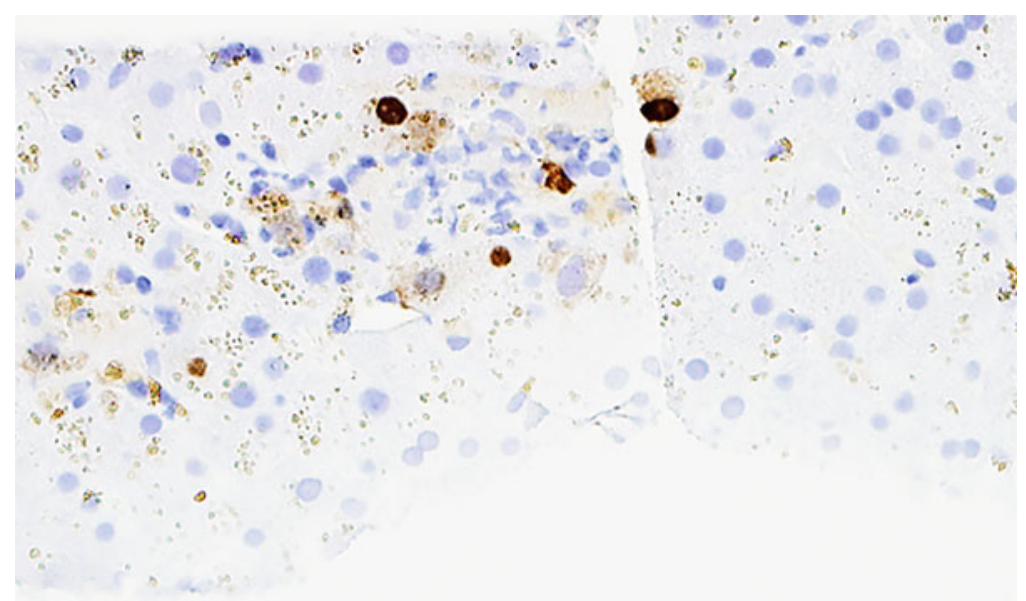

Fig. 3.2 Immunohistochemical staining permits confirmation of human adenovirus infection in tissue sections. In this example, a murine-derived pan-adenoviral antibody was used for detection of adenoviral antigens within a liver core biopsy section. Intense nuclear staining and less intense cytoplasmic staining are observable. Bile crystals are also seen dispersed throughout the tissue, which highlights the importance of careful interpretation of immunohistochemistry stains, especially in tissues in which endogenous pigment granules (e.g., bile, lipofuscin, anthracotic pigment) are commonly found, as some pigments may be confused with positive immunohistochemical staining. Original magnification, $400 \times$ 


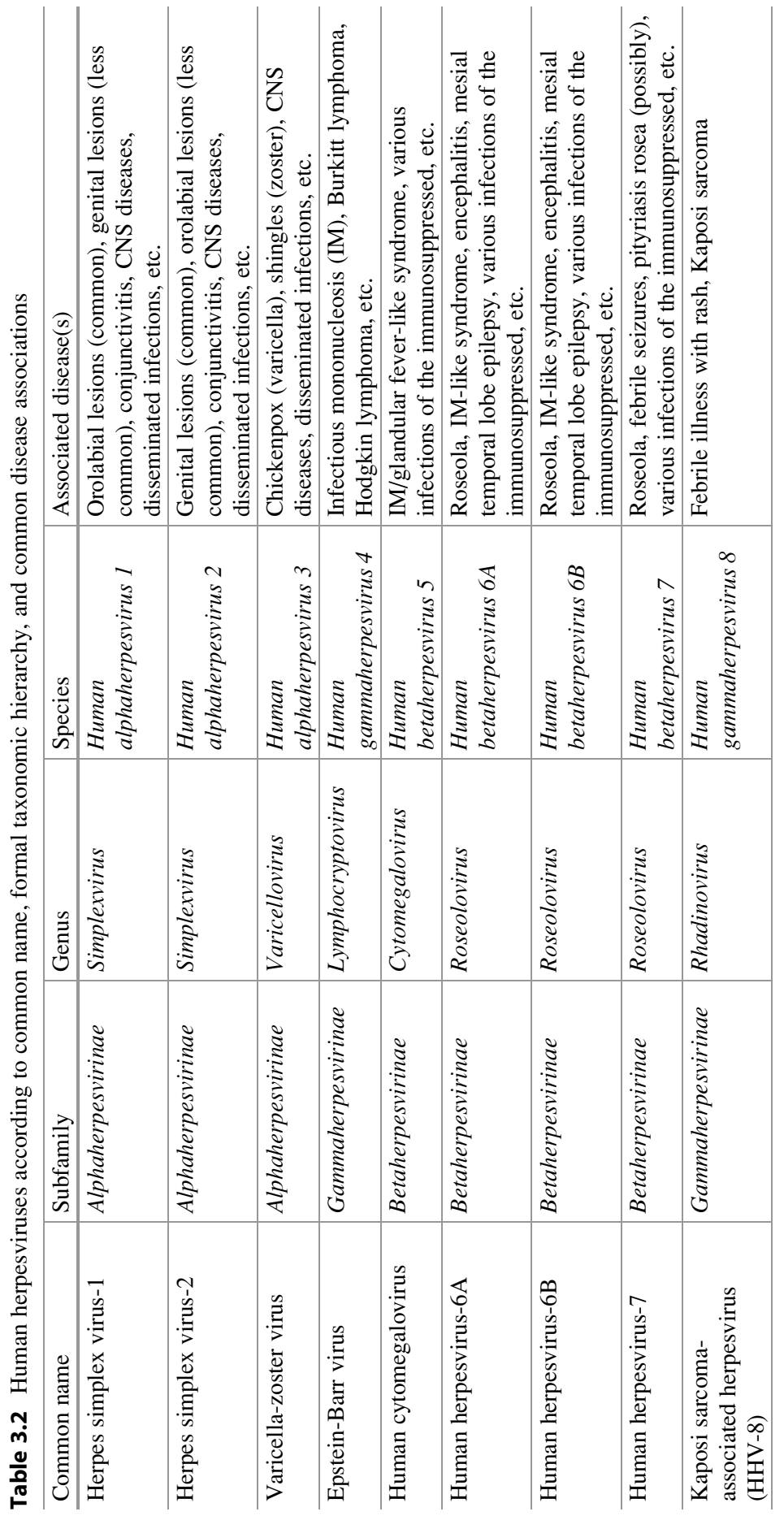


tegument within the space between the viral membrane and the nucleocapsid. Herpesvirus genomes contain linear, monopartite dsDNA that ranges in length from approximately 120-140 kbp. As with many other DNA viruses, herpesvirus replication occurs within the nucleus, and infection with many of these viruses results in obvious cytopathic effects. Many herpesviruses, including HSV and CMV, can be detected by immunohistochemistry (Figs. 3.3, 3.4, 3.5, 3.6, 3.7, 3.8, 3.9, 3.10, 3.11, and 3.12).

\subsection{Human Papillomaviruses}

The family Papillomaviridae is comprised of 49 genera and numerous species of nonenveloped, dsDNA viruses containing genomes of approximately $8 \mathrm{kbp}$ in length that produce particles that measure approximately $60 \mathrm{~nm}$ in size. Interestingly, papillomaviral genomes are complexed with cellular histones, a feature also seen in polyomaviruses. Human papillomaviruses (HPV) are the causative agents of warts, genital cancers, anal dysplasia, focal epithelial hyperplasia, oropharyngeal cancer, and a host of other dermatologic and mucous membrane-associated diseases. Of the 170 types of HPV currently recognized, only a small subset is associated with head, neck, anal, and genital cancers (e.g., HPV 16, 18, 31, 45).

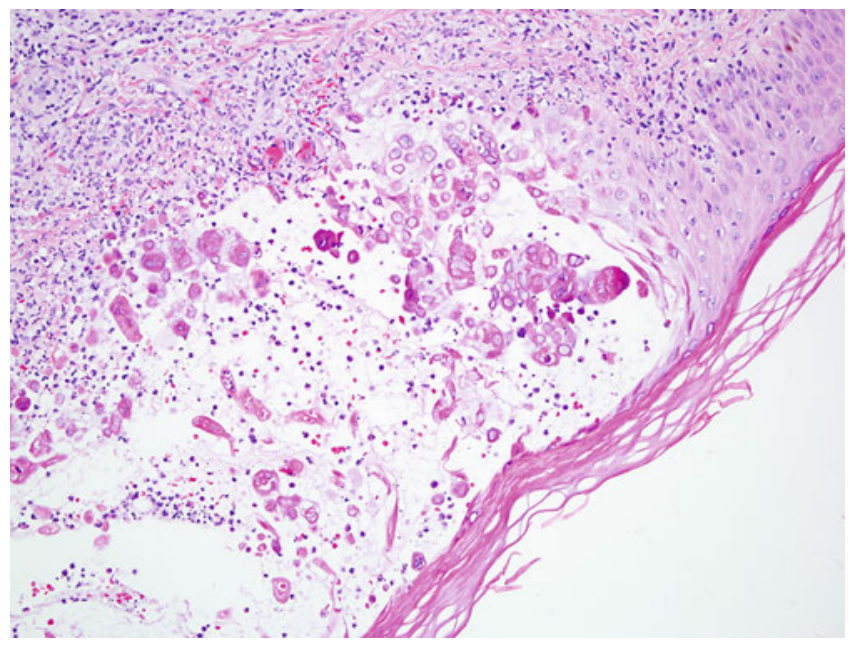

Fig. 3.3 Herpes simplex viruses-1 and -2 (HSV-1 and -2) are the causative agents of orolabial and genital herpes, but among other maladies they can also cause conjunctivitis, central nervous system diseases, and disseminated infections in the very young and immunosuppressed. Although HSV-1 and HSV-2 are often attributed to orolabial and genital herpes, respectively, detection of HSV-1 in genital lesion specimens and HSV-2 in orolabial lesion specimens is not uncommon. Typical cytopathic effects seen in HSV-infected cells include nuclear enlargement, margination of chromatin, nuclear molding, and multinucleation resulting from fusion of adjacent infected cells. The above photomicrograph of an H\&E-stained skin biopsy section reveals the presence of numerous HSV-infected cells, especially around the periphery of the lesion, and an acute inflammatory infiltrate admixed with necrotic debris. Original magnification, $200 \times$ 


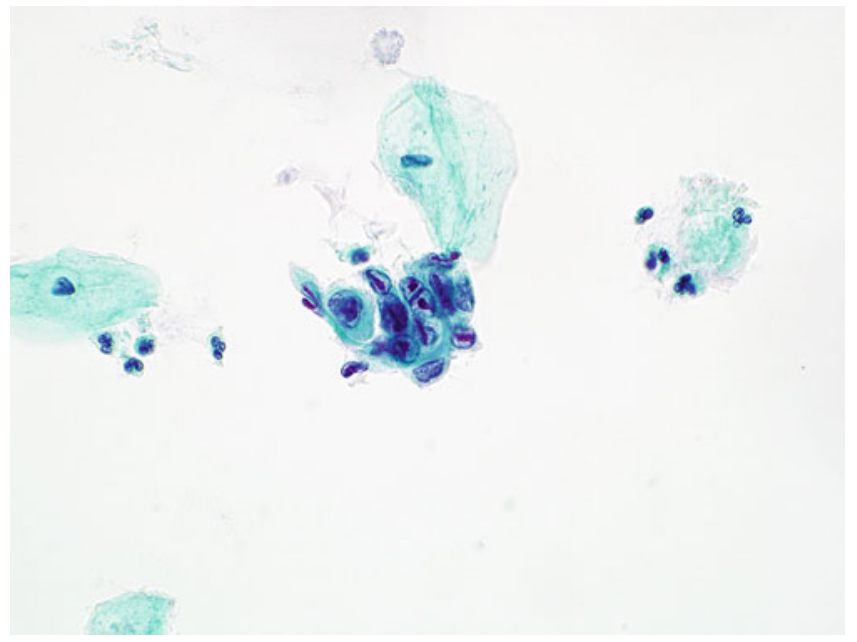

Fig. 3.4 Numerous HSV-infected epithelial cells displaying characteristic cytopathic effects are seen in this Papanicolaou-stained cervical brush specimen. Prominent, dense intranuclear viral inclusion bodies surrounded by marginated chromatin are seen in many of the infected cells. In addition, multinucleation and nuclear molding are apparent. Immunohistochemistry staining using HSV-1- and HSV-2-specific primary antibodies can distinguish infection with these two viruses if warranted. Original magnification, $600 \times$

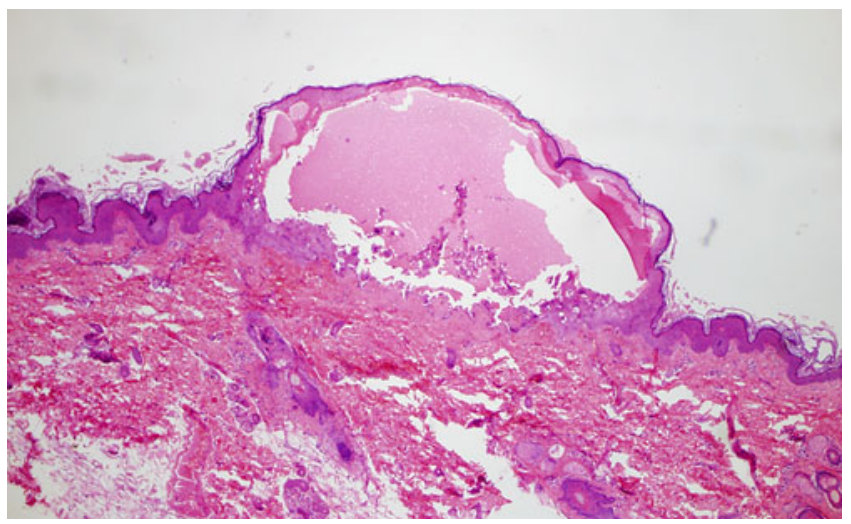

Fig. 3.5 Low-magnification view of a skin biopsy section from a patient with varicella (chickenpox) showing an intraepidermal vesicle containing edema, necrotic debris, acantholytic squamous cells, and neutrophils. Original magnification, $40 \times$ 


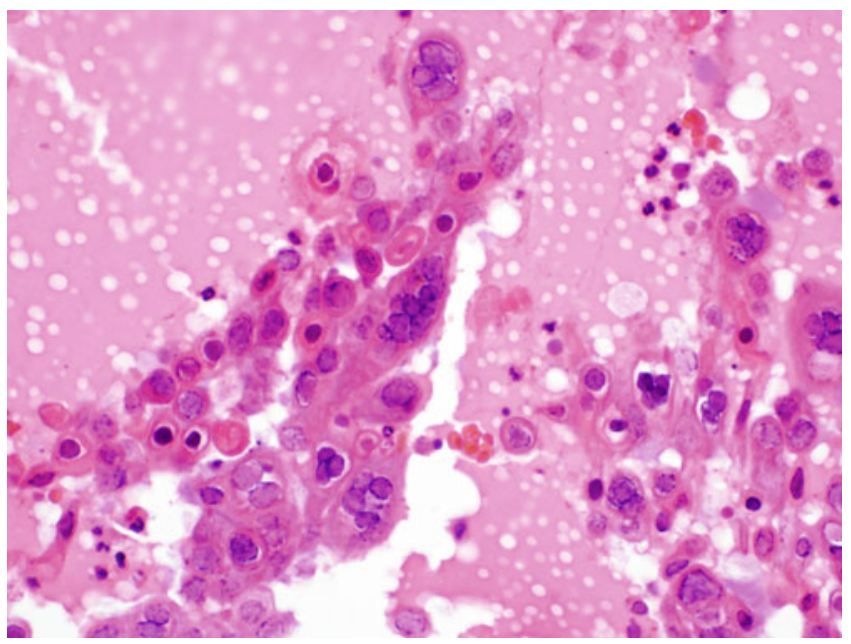

Fig. 3.6 Higher-power view of the skin biopsy shown in Fig. 3.5 reveals the presence of numerous varicella zoster-infected cells displaying cytopathic effects within edema fluid. Salient morphologic features also include fusion of neighboring infected cells to produce multinucleate giant cells, nuclear enlargement with margination of chromatin, and molding of adjacent nuclei. Infections with HSV and varicella-zoster virus induce identical cytopathic effects, but immunohistochemistry permits differentiation of $\mathrm{HSV}$ and varicella-zoster infections. Original magnification, $400 \times$

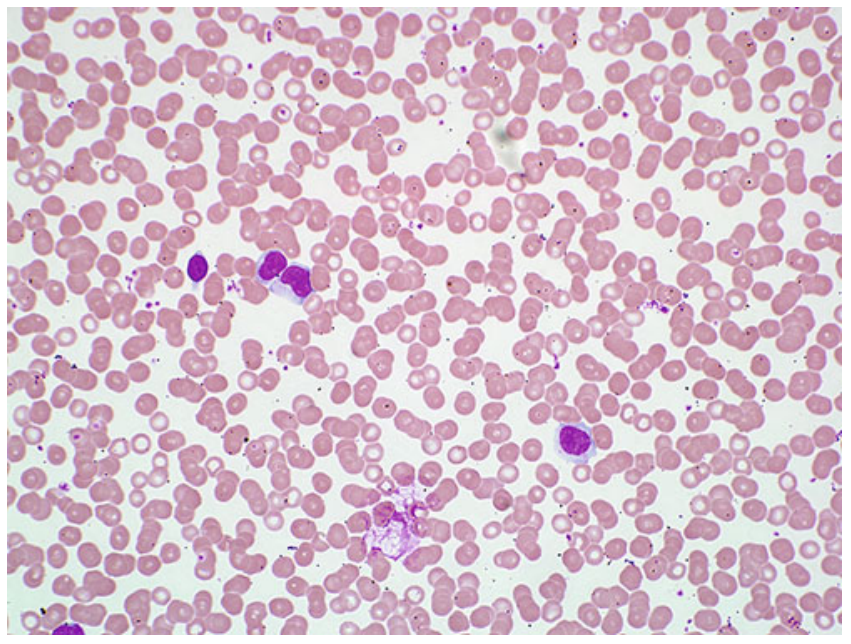

Fig. 3.7 Epstein-Barr virus (EBV) is the principal causative agent of infectious mononucleosis (IM), a disease that primarily affects adolescents and young adults (e.g., college students). EBV is also associated with a number of malignant neoplastic diseases (e.g., Burkitt lymphoma, nasopharyngeal carcinoma) and post-transplant lymphoproliferative disorder, the latter occurring in both hematopoietic stem cell and solid organ transplant recipients. Typical symptoms of IM include fever, pharyngitis, cervical and axillary lymphadenitis, extreme fatigue, and hepatosplenomegaly, among others. Because lesions are generally not produced in primary Epstein-Barr virus infection, histopathology is generally of little value when diagnosing infectious mononucleosis. Instead, immunoserologic testing is the mainstay for IM diagnosis. In most cases of IM, examination of peripheral blood smears reveals the presence of atypical lymphocytes such as those seen in this Wright-Giemsa-stained preparation. Original magnification, 500× 


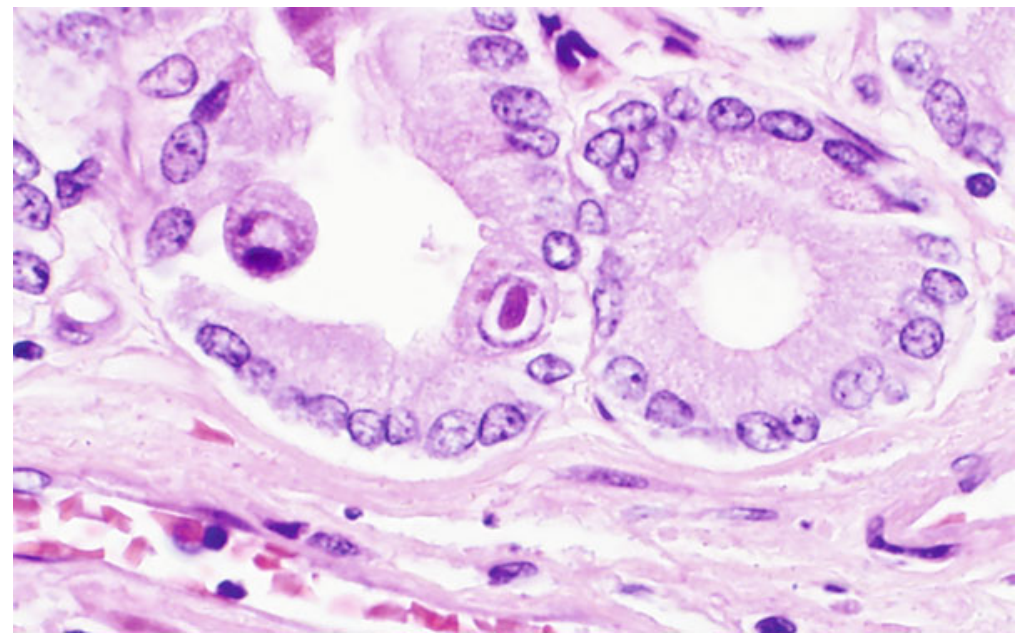

Fig. 3.8 Primary exposure of immunocompetent hosts to human cytomegalovirus (CMV) can result in either a subclinical infection or one with mild, IM-like symptoms. Reactivation of latent infections during states of immunosuppression can lead to focal or disseminated infections that range in severity from mild to fatal. Cytopathic features of CMV infection include cytomegaly and the presence of nuclear and/or cytoplasmic inclusions. The photomicrograph above shows a characteristic "owl's eye" inclusion within the nucleus of a CMV-infected colonic epithelial cell. This inclusion consists of a central solitary viral inclusion surrounded by a zone of pallor, which is surrounded by chromatin that is apposed to the inner leaflet of the nuclear membrane. $\mathrm{H} \& \mathrm{E}$ stain; original magnification, $600 \times$

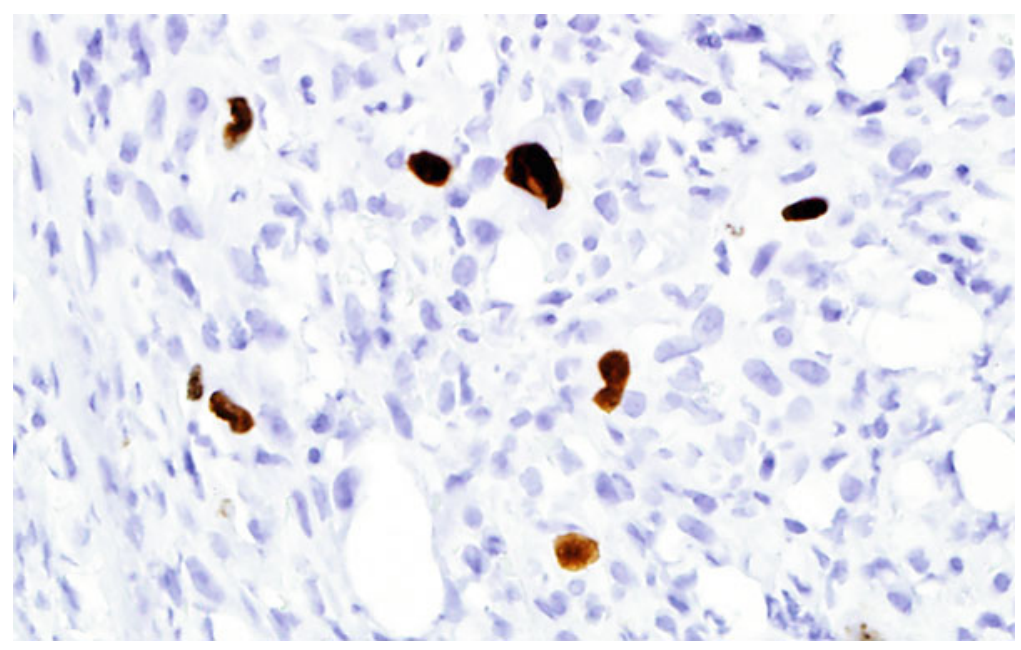

Fig. 3.9 Immunohistochemical staining permits confirmation of CMV infection in tissue sections. In this example, an anti-CMV immediate early antigen monoclonal antibody was used for detection of CMV infected cells. Brown staining highlights the presence of CMV immediate early antigens within the nuclei of colonic stromal cells. Original magnification, $600 \times$ 


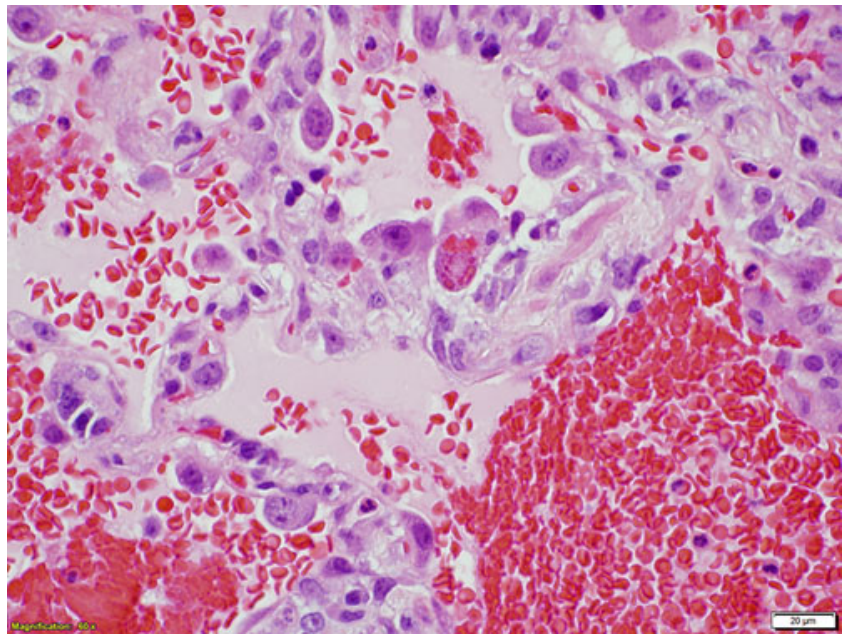

Fig. 3.10 Cytoplasmic CMV inclusions (center) often stain deeply eosinophilic when stained with $\mathrm{H} \& \mathrm{E}$ and appear as one or many smooth granules within the cytoplasmic compartment of infected cells. Original magnification, $600 \times$

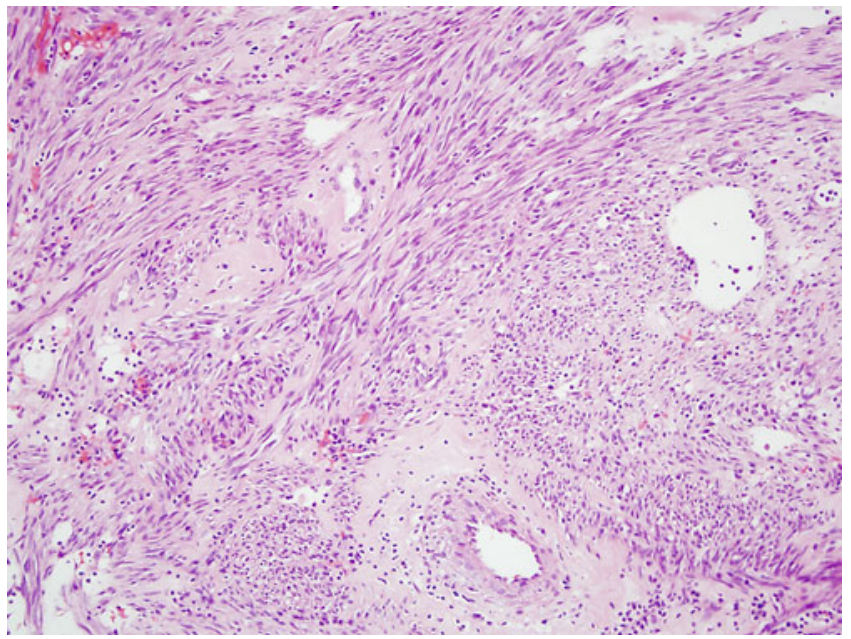

Fig. 3.11 The histopathologic features of Kaposi sarcoma (KS) are rather distinctive, and KS lesions are generally described based upon the stage (e.g., plaque stage, nodular stage) of tumor maturity. There are also several histopathologic variants of KS, including anaplastic, ecchymotic, intravascular, keloidal, and pyogenic-granuloma-like, among others. Lesions appear as dermal nodules comprised of proliferating endothelial cells that create slit-like vascular spaces and spindle cells forming fascicles, sometimes likened to schools of fish. The image above of an H\&E-stained skin biopsy section from a KS patient shows a dermal tumor composed of slightly atypical spindle cells in sheets and fascicles with focal slit-like vascular lumen formation. Original magnification, $200 \times$ 


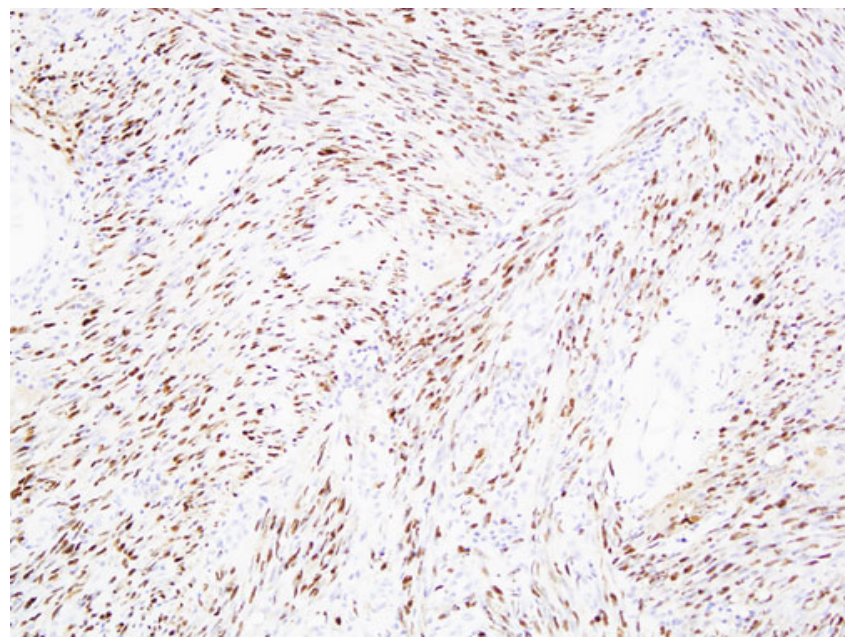

Fig. 3.12 Immunohistochemical staining permits confirmation of HHV-8 infection in tissue sections. In this example, immunohistochemical staining using an HHV-8 latent nuclear antigen 1 antibody reveals prominent nuclear staining and less intense cytoplasmic staining in infected spindle cells. Original magnification, $200 \times$

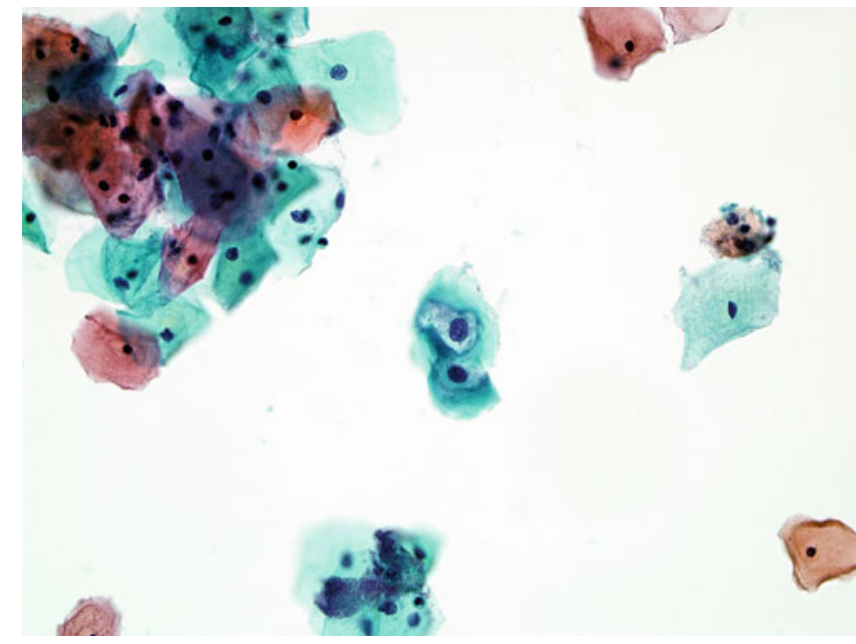

Fig. 3.13 Exfoliated HPV-infected epithelial cells (center) often demonstrate nuclear enlargement, nuclear hyperchromasia, irregular nuclear membrane contouring, and the presence of a perinuclear halo. These cells are called koilocytes, and their presence within cytopathologic and histopathologic preparations should prompt typing of the strain to ascertain the risk for cancer development to the infected patient. Papanicolaou stain; original magnification, $400 \times$

Replication of HPV is restricted to stratified epithelial basal cells; therefore, efforts to detect HPV should focus largely on molecular and histopathologic methods using exfoliative cytologic preparations and tissue biopsies (Figs. 3.13, 3.14 and 3.15). 


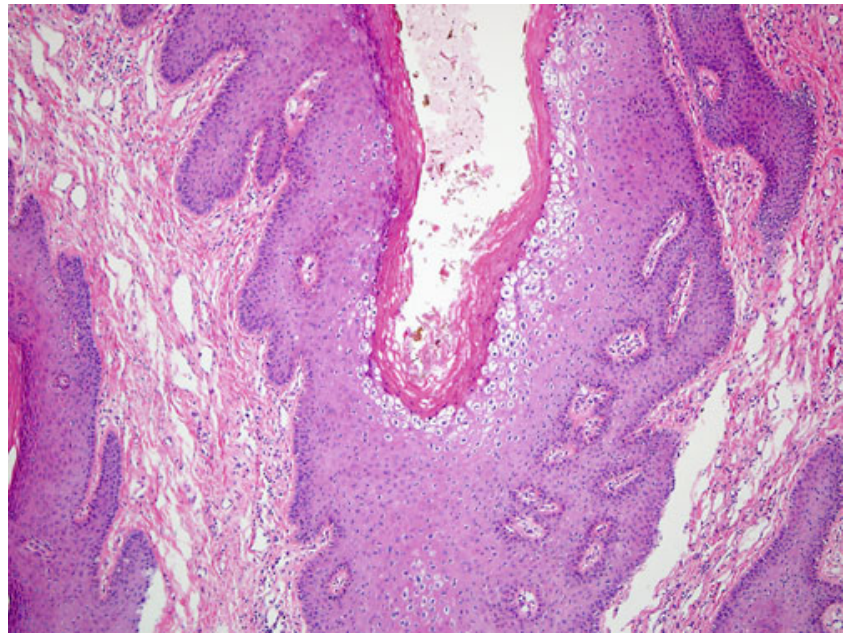

Fig. 3.14 Diffuse epidermal hyperplasia and numerous fibrovascular stalks are notable in H\&Estained sections of warts. In addition, numerous koilocytes are seen within the corneum spinosum. Original magnification, $100 \times$

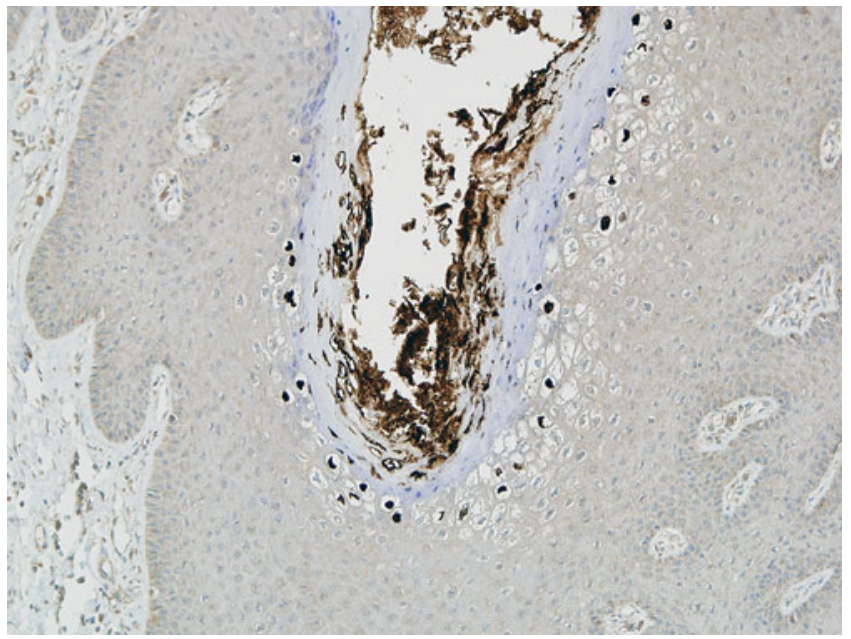

Fig. 3.15 Immunohistochemical staining permits confirmation of human papilloma virus (HPV) infection in tissue sections. In this photomicrograph, HPV antigens are detectable within the stratum corneum and within the nuclei of koilocytes present in the stratum spinosum. Original magnification, $200 \times$ 


\subsection{Human Parvoviruses}

Parvoviruses are nonenveloped viruses that possess short (4-6 kbp) linear ssDNA genomes. Parvoviral particles are among the smallest known, with average sizes ranging from approximately $18-26 \mathrm{~nm}$. To date, only two parvoviruses, human parvovirus B19 and human bocavirus, are known to cause human disease. Human parvovirus B19 (Primate erythroparvovirus 1) is the causative agent of erythema infectiosum (fifth disease), a common childhood illness, and human bocavirus (Primate bocaparvovirus 1 and 2) has been suggested to cause gastroenteritis and lower respiratory tract infections. Parvoviruses, like many other DNA viruses, replicate within the cell nucleus and cause morphologic alterations, including nuclear swelling, chromatin margination, and inclusion production (Figs. 3.16 and 3.17).

\subsection{Human Polyomaviruses}

To date, there have been at least 13 species of human polyomavirus, including BK polyomavirus (Human polyomavirus1), JC polyomavirus (Human polyomavirus 2), and Merkel cell polyomavirus (Human polyomavirus 5) shown to infect humans. Most species are not pathogenic, but those that are cause very mild diseases in immunocompetent hosts, most commonly young children. Severe polyomavirus-

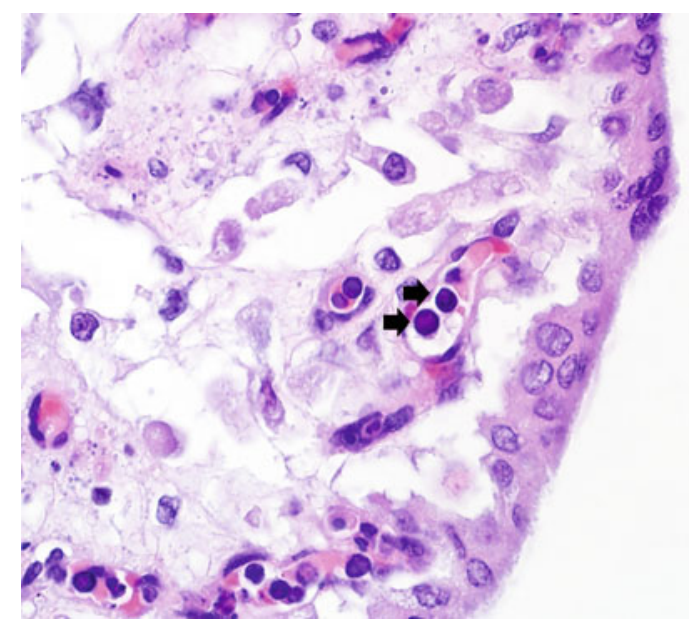

Fig. 3.16 Human parvovirus B19 (B19) is capable of attaching to and penetrating host cells expressing $\mathrm{P}$ antigen, which include erythroid precursor cells, endothelial cells, megakaryocytes, and others. Productive infection seems to be limited to the erythroid precursors BFU-E (erythroid burst-forming unit) and CFU-E (erythroid colony-forming unit) within the bone marrow and sites of extramedullary hematopoiesis. Like with many other DNA viruses, viral replication and particle assembly occur within the nucleus, leading to peripheral aggregation of chromatin and formation of variably-sized eosinophilic viral inclusions (arrows). Original magnification, 1000× 


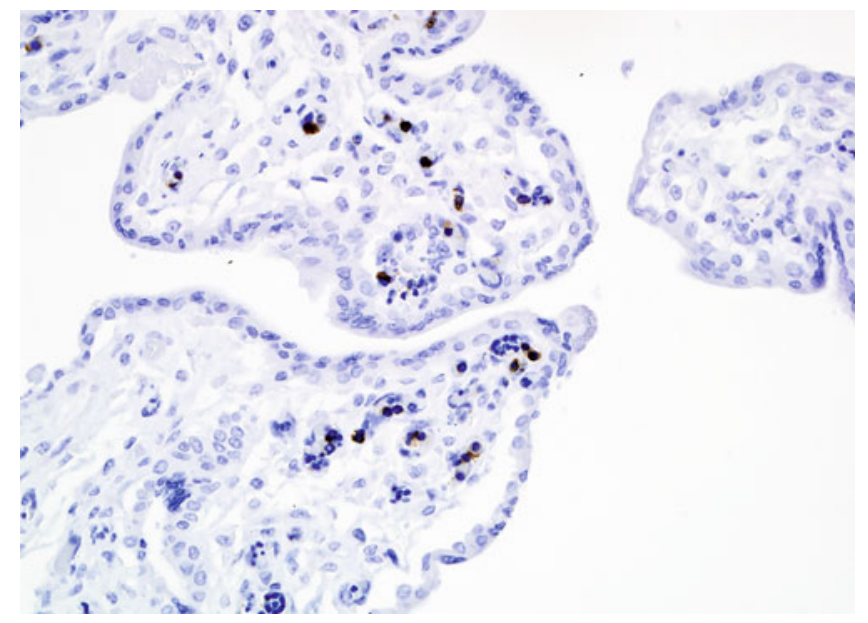

Fig. 3.17 Immunohistochemical staining permits confirmation of B19 infection in tissue sections. In this example, intense brown staining within the nuclei and lighter cytoplasmic staining highlight B19-infected cells. Original magnification, 200×

associated infections are most common in immunosuppressed hosts, including kidney and hematopoietic stem cell transplant recipients, and the spectrum of diseases in these individuals includes progressive multifocal leukoencephalopathy, nephropathy, hemorrhagic cystitis, and Merkel-cell carcinoma. Polyomavirus particles are roughly $50 \mathrm{~nm}$ in size, are nonenveloped, and contain a dsDNA genome that measures approximately $5 \mathrm{kbp}$ in length. Like with papillomaviruses, the genomes of polyomaviruses are complexed with histones derived from host cells. Replication of polyomaviral genomes and assembly of new particles occurs within the cell nucleus (Figs. 3.18, 3.19 and 3.20).

\subsection{Paramyxoviruses}

Several viruses that are classified in the family Paramyxoviridae are human pathogens and cause diseases that range in severity from relatively mild respiratory tract infections to severe, life-threatening respiratory and central nervous system infections. Viruses belonging to this family that cause human disease are listed in Table 3.3. Like other members of the order Mononegavirales, paramyxoviruses have nonsegmented-ssRNA genomes that measure approximately $15 \mathrm{kbp}$ in length and form complexes with viral structural proteins to produce helical nucleocapsids. Nascent particles bud from the cytoplasmic membrane, during which they are enveloped; resulting particles are roughly spherical or filamentous. Paramyxoviruses are transmitted between humans via aerosolized infectious respiratory secretions, through fomites, and some, the henipaviruses, are transmissible from infected animals such as bats, pigs, and horses (Figs. 3.21 and 3.22). 


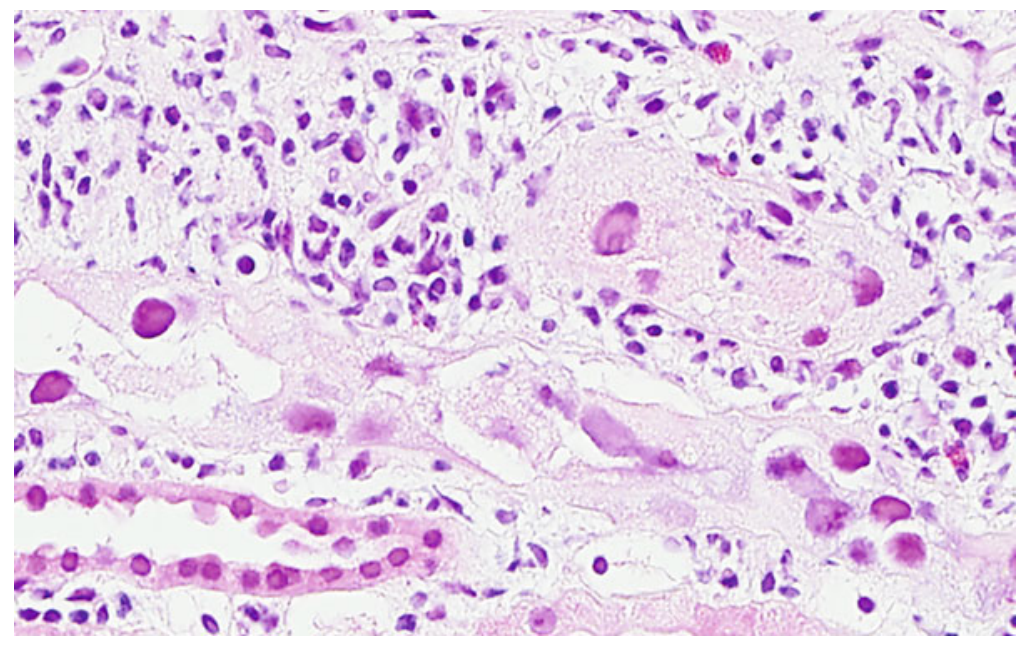

Fig. 3.18 BK polyomavirus infection of renal transplant recipients can result in ureteral stenosis and virus-induced nephropathy, which can lead to graft loss. Hemorrhagic cystitis, another manifestation of urogenital BK polyomavirus infection, is more common in hematopoietic stem cell transplant recipients, especially within the first few months following transplantation. Intranuclear viral replication leads to displacement of the cellular chromatin, imparting darker peripheral staining of the nucleus. As viral replication progresses, the accumulation of progeny particles leads to swelling of the nucleus and eventual degeneration of the nuclear membrane. Both early- and late-stage cytopathic effects are apparent in the renal tubular epithelium and surrounding cells in the above photomicrograph of an H\&E-stained kidney biopsy section from a renal transplant patient with tubulointerstitial nephritis. Original magnification, $400 \times$

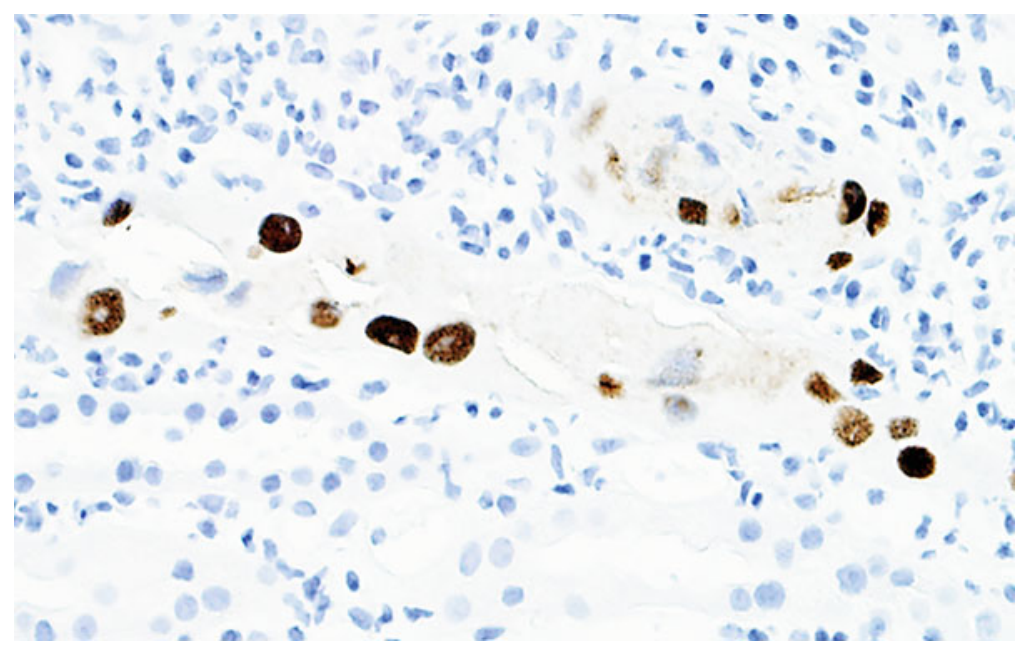

Fig. 3.19 Immunohistochemical staining permits confirmation of BK polyomavirus infection in tissue sections. In this example, BK polyomavirus antigens are detected within the nucleus of infected renal tubular epithelial cells. Original magnification, $400 \times$ 


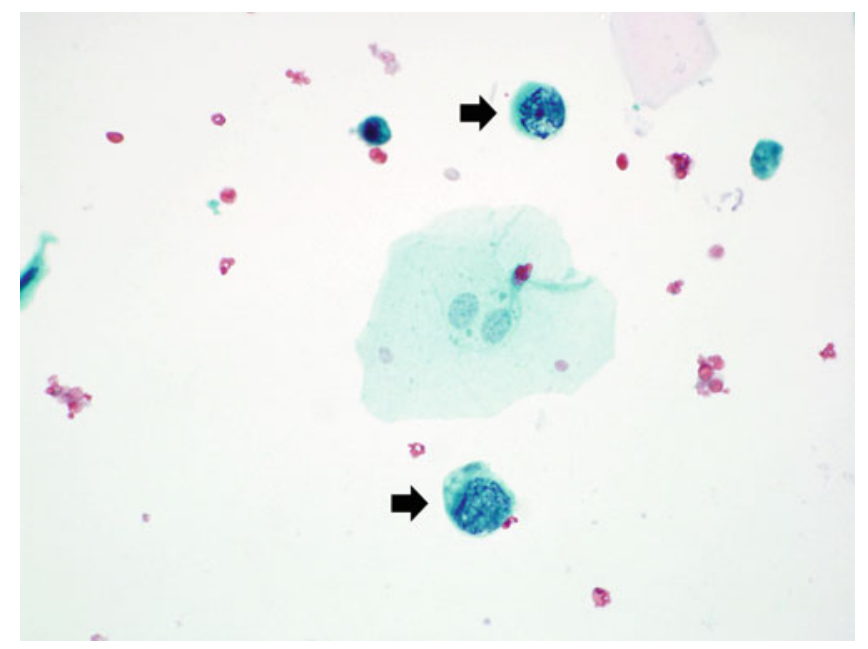

Fig. 3.20 A Papanicolaou-stained urine sediment containing exfoliated BK polyomavirusinfected urothelial cells (decoy cells; arrows) from a patient with hemorrhagic cystitis. Decoy cells were given their name because of their resemblance to malignant urothelial cells. They characteristically have a large nucleus that may contain one or more basophilic inclusions surrounded by chromatin, which sometimes gives the nucleus a ground-glass appearance. Original magnification, $600 \times$

Table 3.3 Examples of human-pathogenic paramyxoviruses listed according to common name, formal taxonomic hierarchy, and disease associations

\begin{tabular}{l|l|l|l}
\hline $\begin{array}{l}\text { Common } \\
\text { name }\end{array}$ & Genus & Species & Associated disease(s) \\
\hline $\begin{array}{l}\text { Respiratory } \\
\text { syncytial } \\
\text { virus }\end{array}$ & Orthopneumovirus & $\begin{array}{l}\text { Human } \\
\text { orthopneumovirus }\end{array}$ & $\begin{array}{l}\text { Mild-to-severe bronchiolitis and } \\
\text { pneumonia, coryza }\end{array}$ \\
\hline $\begin{array}{l}\text { Human } \\
\text { parainfluenza } \\
\text { virus }\end{array}$ & $\begin{array}{l}\text { Respirovirus } \\
\text { Rubulavirus }\end{array}$ & $\begin{array}{l}\text { Human } \\
\text { respirovirus } 1 \\
\text { Human } \\
\text { respirovirus } 3 \\
\text { Human } \\
\text { rubulavirus } 2 \\
\text { Human } \\
\text { rubulavirus } 4\end{array}$ & $\begin{array}{l}\text { Mild-to-severe upper and lower } \\
\text { respiratory tract infections (e.g., } \\
\text { croup), meningitis (rare) }\end{array}$ \\
\hline Mumps virus & Rubulavirus & $\begin{array}{l}\text { Mumps } \\
\text { rubulavirus }\end{array}$ & $\begin{array}{l}\text { Mumps, meningoencephalitis } \\
\text { (rare) }\end{array}$ \\
\hline Measles virus & Morbillivirus & $\begin{array}{l}\text { Measles } \\
\text { morbillivirus }\end{array}$ & $\begin{array}{l}\text { Measles, subacute sclerosing } \\
\text { panencephalitis }\end{array}$ \\
\hline Hendra virus & Henipavirus & $\begin{array}{l}\text { Hendra } \\
\text { henipavirus }\end{array}$ & $\begin{array}{l}\text { respiratory infections, meningitis, } \\
\text { encephalitis }\end{array}$ \\
\hline Nipah virus & Henipavirus & $\begin{array}{l}\text { respiratory infections, meningitis, } \\
\text { encephalitis }\end{array}$ \\
\hline
\end{tabular}




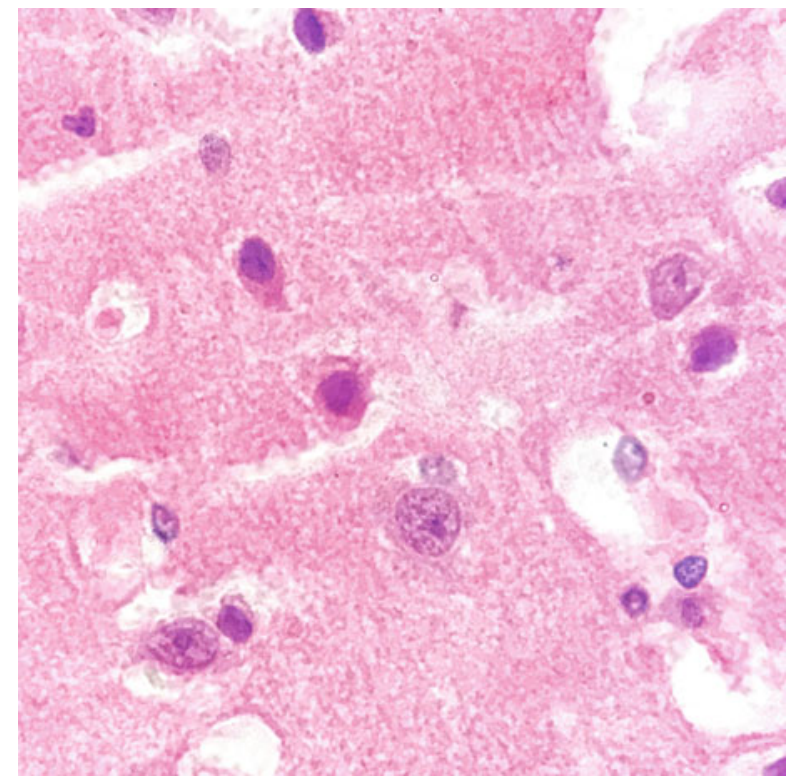

Fig. 3.21 Although relatively uncommon in the developed world, measles remains a significant cause of human morbidity and mortality throughout the developing world, where vaccination against the virus is uncommon or inaccessible. The majority of measles virus infections occur during childhood and are characterized by fever, nonproductive cough, conjunctivitis, coryza, and a maculopapular rash. The disease is generally self-limiting, but serious or fatal sequelae, including pneumonia and subacute sclerosing panencephalitis (SSPE), can occur. In this photomicrograph of an H\&E-stained section of brain tissue from a patient who died from measles inclusion-body encephalitis several years after initial measles virus infection, multiple measles virus-infected neurons are present. In this example, the cytoplasm of infected neurons is shrunken and deeply eosinophilic and a few eosinophilic inclusions are evident. In measles-infected lymphoid tissue, large multinucleate cells (Warthin-Finkeldey cells) are usually seen. Original magnification, $1000 \times$

\subsection{Poxviruses}

Some poxviruses (e.g., molluscum contagiosum virus) are common human pathogens; however, natural variola virus transmission has been eradicated from the planet, and the last human cases of smallpox were witnessed in the later part of the 1970s. Poxviruses possess some of the largest genomes of any virus known to infect humans. On average, the linear dsDNA genomes of these viruses measure approximately $170-250 \mathrm{kbp}$ in length and encode numerous proteins. Unlike many other DNA viruses, replication of poxvirus genomes and particle assembly occurs within the cytoplasmic compartment of host cells, a feature that is made possible by viral proteins encoded within poxviral genomes. Consequently, light microscopic examination of stained tissue sections often permits visualization of intracytoplasmic inclusions of poxviruses such as Guarnieri bodies and molluscum bodies seen in variola virus- and molluscum contagiosum virus-infected cells, respectively (Figs. 3.23, 3.24, 3.25 and 3.26). 


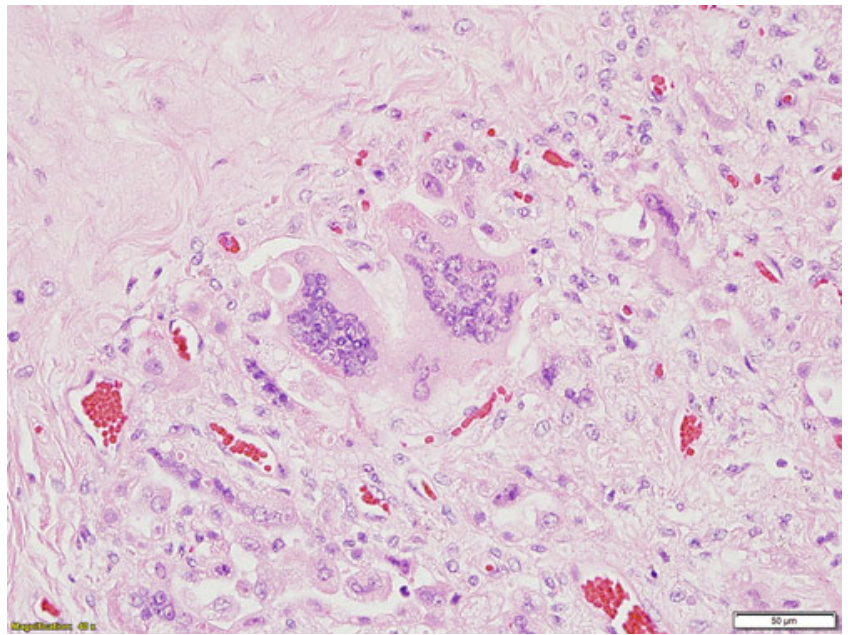

Fig. 3.22 Many infections caused by paramyxoviruses result in the formation of syncytia (above). Infected cells express viral fusion proteins on the cell surface that, at physiologic $\mathrm{pH}$, mediate fusion of the cytoplasmic membranes of adjacent cells. Cell-cell fusion permits the spread of virions from infected cells to naïve cells, which affords virions some level of protection from host defenses. The photomicrograph above shows numerous syncytia in an H\&E-stained section of lung tissue from an infant that died from severe parainfluenza virus infection. Original magnification, $400 \times$

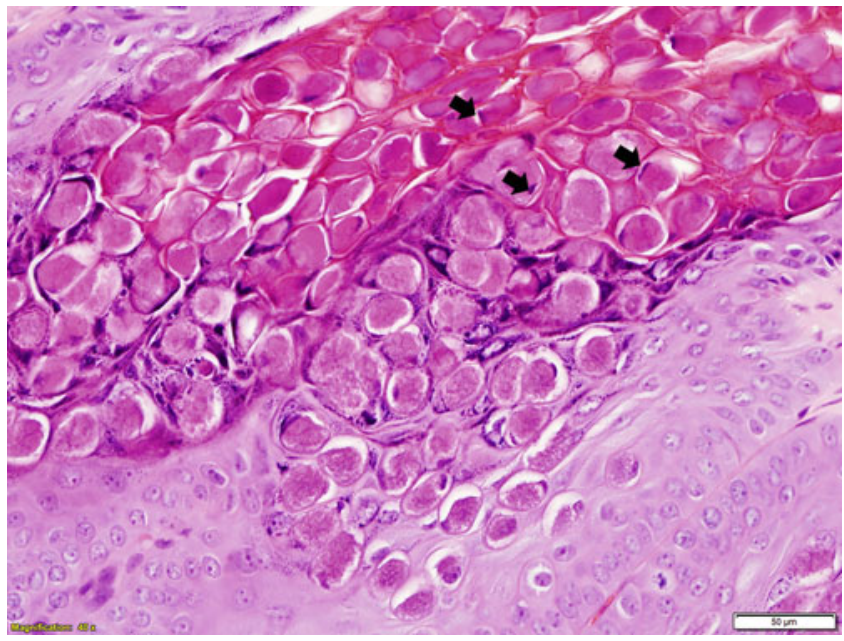

Fig. 3.23 Molluscum contagiosum virus is the agent of a mild and often benign skin disease called molluscum contagiosum. This virus is cosmopolitan in distribution and is transmitted from person-to-person by direct contact and via fomites, such as contaminated towels, razors, and toys. Viral replication is restricted to the epidermis, where it causes enlargement of infected cells, which produce very large and intensely eosinophilic cytoplasmic inclusions (molluscum bodies) that displace organelles. The nucleus of infected cells is often seen pressed against the cytoplasmic membrane, as seen in the H\&E-stained skin biopsy section above (arrows). Original magnification, $400 \times$ 


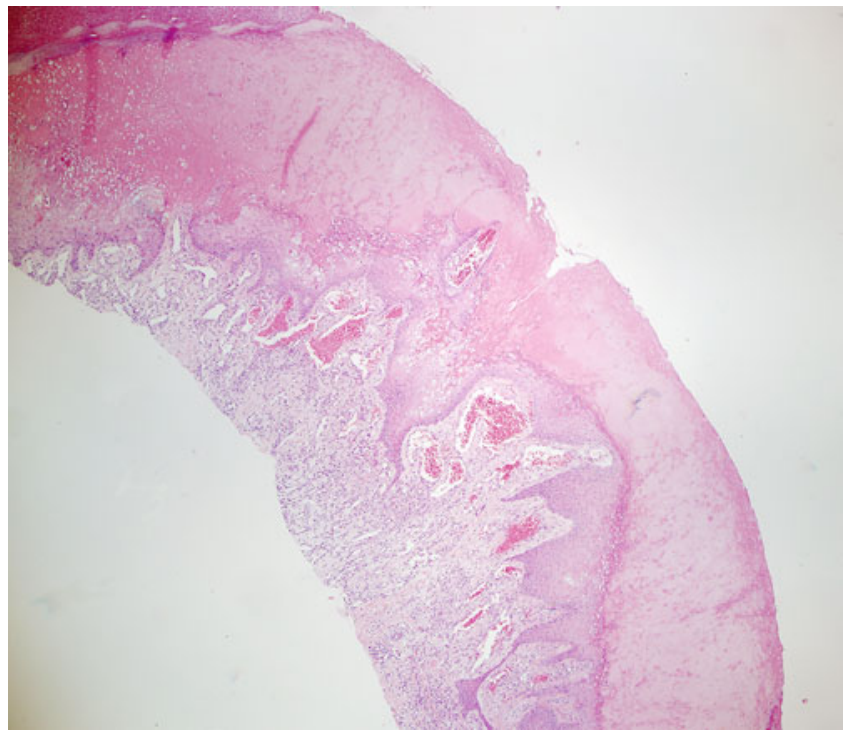

Fig. 3.24 The Orf virus is a zoonotic agent that primarily affects goats and sheep, but other mammals, including humans, can become infected. Transmission of orf virus occurs by direct contact with infected animals, and human infections lead to the formation of one or more papules at sites of infection, which can include the fingers, hands, and arms among other sites. Orf virus infection of humans is generally benign and self-limiting. Salient histopathologic features include spongiosis, ballooning degeneration, and superficial necrosis of the epidermis. High-power examination reveals small, eosinophilic cytoplasmic viral inclusions in some cells. H\&E stain; original magnification, $40 \times$

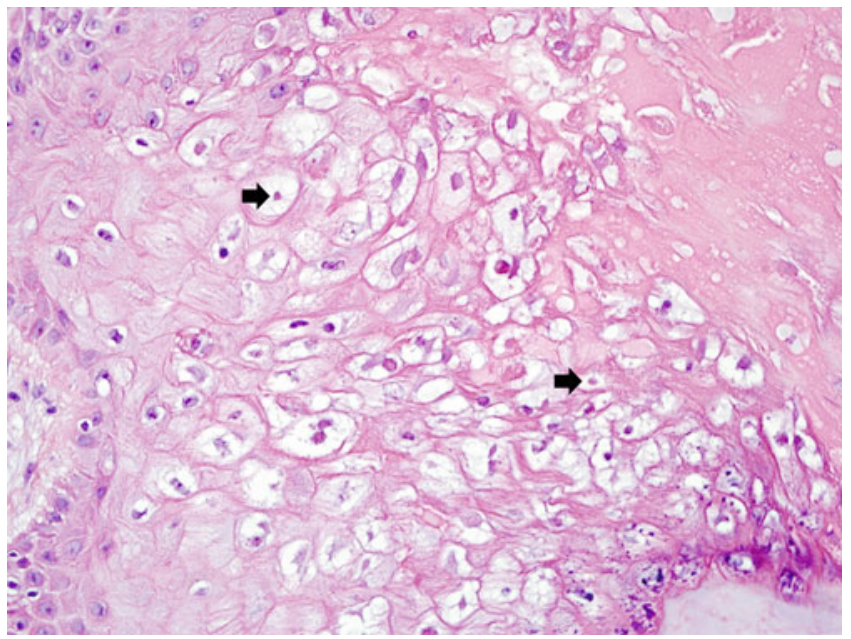

Fig. 3.25 Ballooning degeneration and viral inclusions (arrows) are seen in a high-power photomicrograph of the specimen from Fig. 3.24. Original magnification, $400 \times$ 


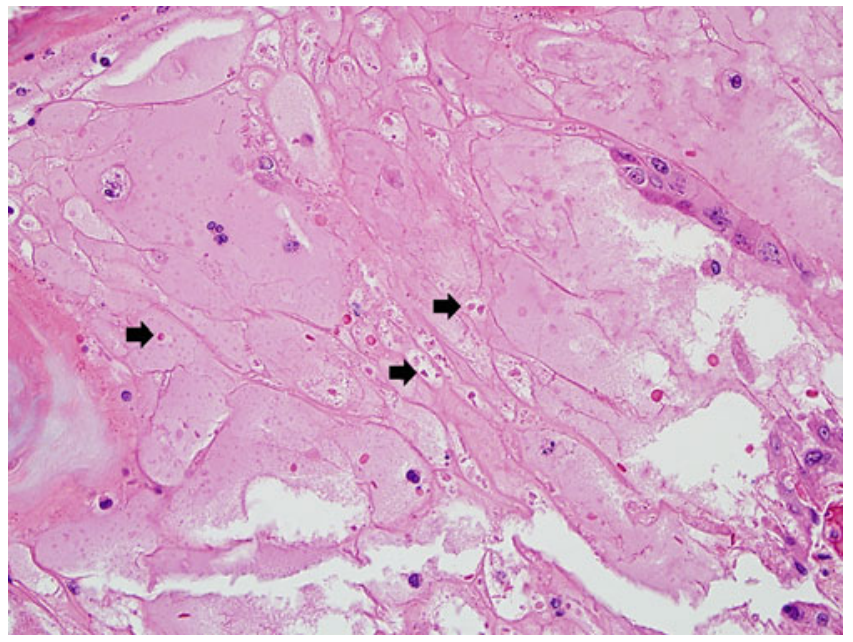

Fig. 3.26 The dermatologic manifestations of smallpox include both raised (vesicular) and flat lesions; the latter predominate in cases of hemorrhagic smallpox. Variola virus has a relatively broad host cell tropism and infects cells of the respiratory tract, endothelial and epithelial cells, hepatocytes, and numerous others. In this example from an archival case dating back to the 1920s, examination of an H\&E-stained skin biopsy section reveals epidermal necrosis with ballooning reticular degeneration, resulting in vesicle formation. Rare intracytoplasmic eosinophilic inclusions (Guarnieri bodies) are visible under high-power magnification (arrows). Original magnification, $400 \times$. (Slide of H\&E-stained tissue provided by Dr. Bobbi Pritt, Division of Clinical Microbiology, Mayo Clinic, Rochester, MN)

\subsection{Hemorrhagic Fever Viruses and Miscellaneous Human-Pathogenic Viruses}

The following figures represent a broad diversity of viruses that can cause hemorrhagic fever or other severe infectious diseases that are rarely encountered in most developed nations. Included among this group are the filoviruses (e.g., Ebola virus), flaviviruses (e.g., yellow fever virus), hantaviruses (e.g., Sin Nombre virus), and rabies virus (Figs. 3.27, 3.28, 3.29 and 3.30). 


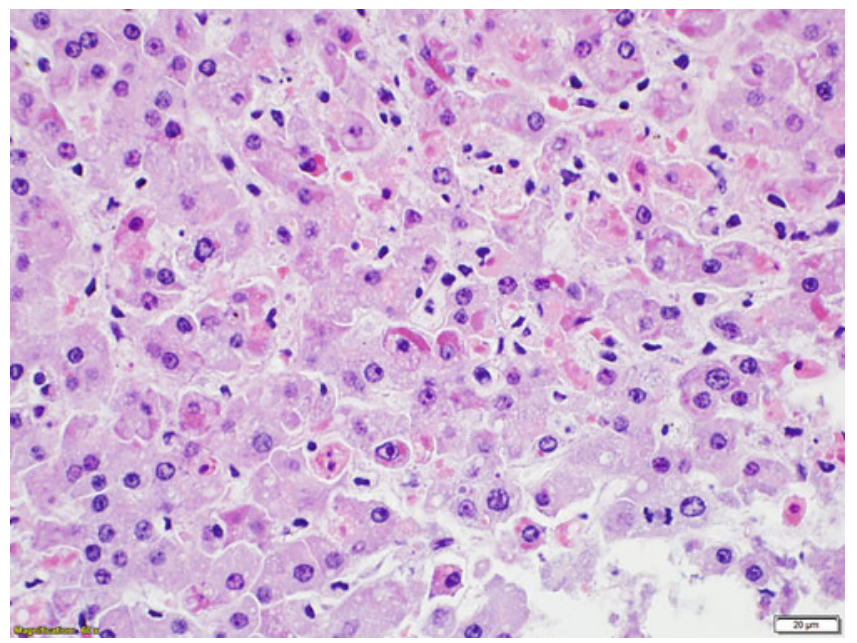

Fig. 3.27 Filoviruses, including ebolaviruses and marburgviruses, cause severe and often lifethreatening infectious diseases in humans and other animals. Hallmarks of filoviral infections include the abrupt onset of fever, weakness, and severe head and body aches followed by the development of a rash, severe gastrointestinal symptoms, red eyes, and in a variable proportion of infected individuals, eventual development of hemorrhagic manifestations, including bleeding of the gums, the gastrointestinal tract, and from needle puncture sites. The incubation period for filoviral disease ranges from a few days to a few weeks following exposure, and infected individuals are contagious once symptoms appear. Ebola virions have been recovered from various body fluids, including blood, feces, urine, breast milk, and semen, among others. Filoviruses have a broad cell tropism; susceptible and permissive cells include monocytes, macrophages, dendritic cells, hepatocytes, endothelial cells, adrenal cortex cells, and others. The image above is a highpower view of an H\&E-stained liver core biopsy section from a patient infected with Zaire ebolavirus (Ebola virus). In this example, there exists the conspicuous absence of a robust acute inflammatory response and the presence of apoptotic lymphocytes. Numerous Ebola virus-infected hepatocytes are present, and many contain eosinophilic, rope-like, football-shaped, or pleomorphic cytoplasmic inclusions. Original magnification, 600×. (Slide of H\&E-stained tissue section provided by Dr. Sherif Zaki, Infectious Diseases Pathology Branch, U.S. Centers for Disease Control and Prevention, Atlanta, GA) 


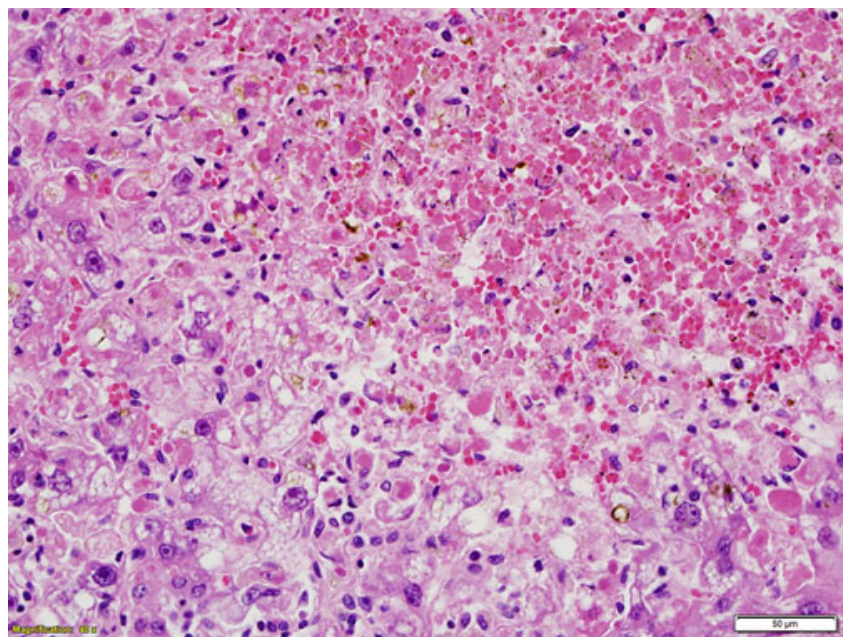

Fig. 3.28 The family Flaviviridae includes numerous viruses associated with hemorrhagic fever, including yellow fever virus, dengue viruses, Alkhurma hemorrhagic fever virus, Omsk hemorrhagic fever virus, and Kyasanur forest disease virus. These viruses are zoonotic agents that are largely transmitted by contact with infected animals or through the bites of infected mosquitoes or ticks. The specific means of transmission, symptoms, treatment, and prevention measures for the various viruses within this family are beyond the scope of this text, but refer to the section "Suggested Reading" for additional details. The photomicrograph above is an H\&E-stained liver biopsy section from a patient with yellow fever and shows diffuse hepatocyte necrosis, parenchymal hemorrhage, and numerous Councilman bodies (apoptotic hepatocytes). Original magnification, $400 \times$. (Slide of H\&E-stained tissue section provided by Dr. Sherif Zaki, Infectious Diseases Pathology Branch, U.S. Centers for Disease Control and Prevention, Atlanta, GA) 


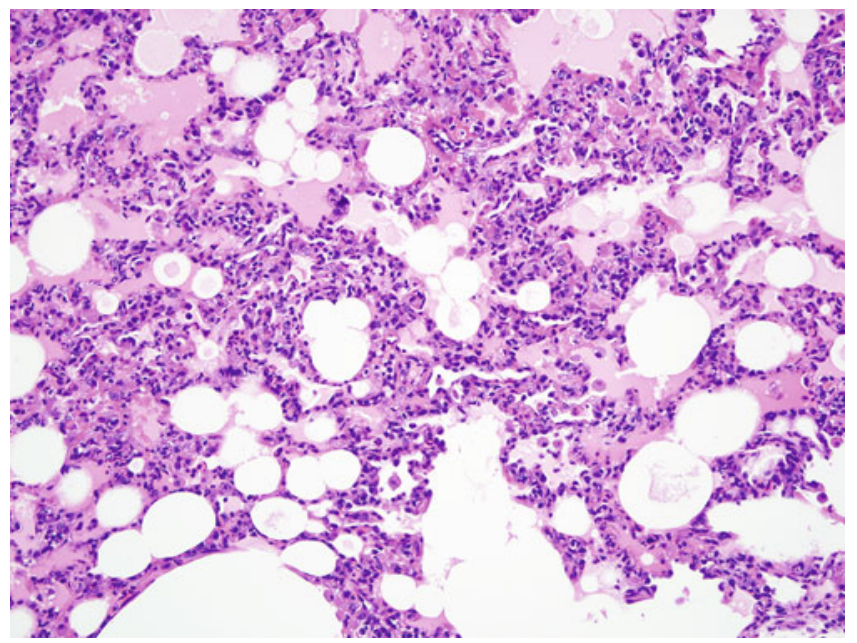

Fig. 3.29 Numerous hantaviruses are known to cause cardiopulmonary disease and hemorrhagic fever with renal syndrome. In nature, these viruses are carried by rodents such as deer mice, and human infections occur by inhalation of virion-laden aerosols generated by disturbance of rodent excreta. Replication of hantaviruses associated with cardiopulmonary disease occurs within pulmonary vascular endothelial cells, pulmonary macrophages, follicular dendritic cells, and within the vascular endothelium of myocardial capillaries. Cytoplasmic inclusions can be seen within pulmonary vascular endothelial cells, but immunohistochemical staining provides a more specific and reliable means for viral detection. The massive pulmonary edema seen in hantavirus cardiopulmonary syndrome patients is associated with virus-induced impairment of the pulmonary vascular endothelium. Hantavirus particles are enveloped, measure approximately $80-120 \mathrm{~nm}$ in size, and contain a tripartite genome composed of linear-ssRNA molecules. The photomicrograph above is that of an H\&E-stained lung section from a nonhuman primate that was experimentally infected with Sin Nombre virus, the hantavirus associated with the 1993 Four Corners region hantavirus cardiopulmonary syndrome outbreak. Nonhuman primate models provide valuable insight into the pathogenesis and pathology of hantavirus infections, and they also recapitulate the disease processes seen in humans with relatively high fidelity. This photomicrograph shows the intra-alveolar edema and fibrin deposition, hyaline membrane formation, and interstitial pneumonitis. Original magnification, 200×. (Slide of H\&E-stained tissue section provided by Dr. Dana Scott, Chief of Pathology, National Institutes of Health Rocky Mountain Laboratories, Hamilton, MT) 


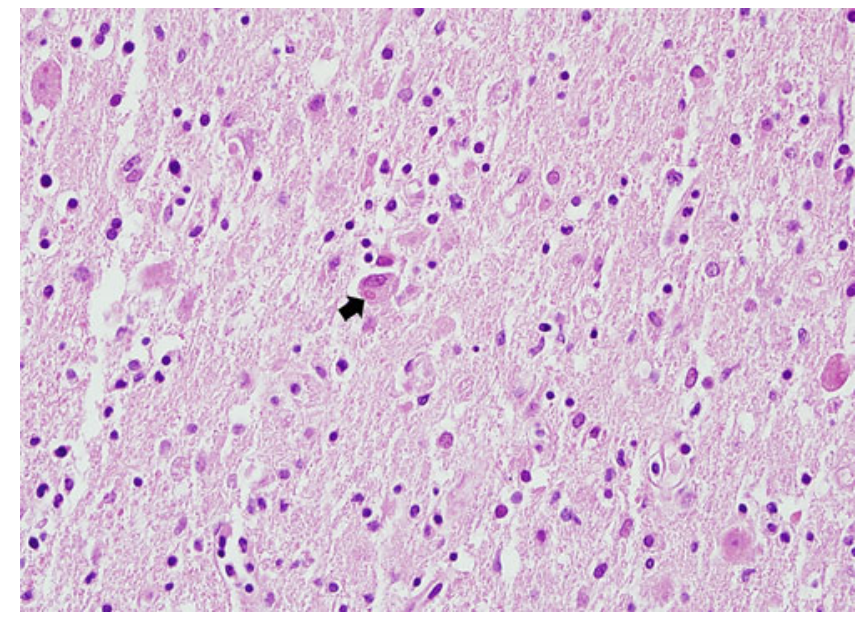

Fig. 3.30 Despite the availability of highly effective postexposure prophylaxis, rabies virus remains a significant cause of human mortality in regions of the world where animal and human vaccines are not readily accessible. Rabies virus is a zoonotic virus that is most frequently transmitted to humans by the bites of infected canids, although a small percentage of human infections result from the bites of other infected carnivores and bats, while an even smaller percentage of infections are transmitted by other means, including through allogeneic tissue transplants received from infected donors. Following inoculation, rabies virus can access the central nervous system via infection of peripheral nerves, which serve as conduits through which rabies virus travels to the brain. Myocytes and presumably other cell types at the site of rabies virus inoculation can also host rabies virus infection, but detection of the virus in these cells is difficult. With the exception of limited tissue necrosis, neuronal loss, and the appearance of characteristic cytoplasmic inclusion bodies (Negri bodies) within infected neurons, rabies virus induces little pathologic change to infected tissues. Rabies virus is a member of the order Mononegavirales, family Rhabdoviridae, and possesses a -ssRNA within a helical nucleocapsid that forms a bullet-shaped particle that is enveloped during budding through the cytoplasmic membrane. The image above is from an H\&E-stained cerebellar section from an adolescent patient that died from rabies. Numerous rabies virus-infected neurons are present within the Purkinje layer, and the arrow points to a Negri body. Original magnification, $400 \times$

Acknowledgments The author wishes to thank Dr. Sherif Zaki (Infectious Diseases Pathology Branch, U.S. Centers for Disease Control and Prevention), Dr. Bobbi Pritt (Division of Clinical Microbiology, Mayo Clinic), and Dr. Dana Scott (National Institutes of Health Rocky Mountain Laboratories) for provision of slides of H\&E-stained tissue sections of Ebola and yellow fever virus-infected tissues, variola virus-infected tissue, and hantavirus-infected nonhuman primate tissue, respectively. In addition, Dr. Relich wishes to thank Drs. Bryan Schmitt, Theodore Kieffer, Matthew Kuhar, Simon Warren, Mercia Gondim, and Dibson Gondim (Department of Pathology and Laboratory Medicine, Indiana University School of Medicine, Indianapolis, IN) for their professional consultations and interpretations of many of the images shown. 


\section{Suggested Reading}

Brackney DE, Armstrong PM. Transmission and evolution of tick-borne viruses. Curr Opin Virol. 2016;21:67-74.

Burke DS. Evolvability of emerging viruses. In: Nelson AM, Horsburgh CR, editors. Pathology of emerging infections 2. Washington, DC: ASM Press; 1998. p. 1-10.

Caruso JL, Childs JM, Howell DN. Surgical pathology and diagnostic cytology of viral infections. In: Jerome KR, editor. Lennette's laboratory diagnosis of viral infections. 4th ed. New York: Informa Healthcare; 2010. p. 151-72.

Dash AP, Bhatia R, Sunyoto T, Mourya DT. Emerging and re-emerging arboviral diseases in Southeast Asia. J Vector Borne Dis. 2013;50(2):77-84.

Feldmann H, Geisbert TW. Ebola hemorrhagic fever. Lancet. 2011;377(9768):849-62.

Goldsmith CS, Whistler T, Rollin PE, Ksiazek TG, Rota PA, Bellini WJ, et al. Elucidation of Nipah virus morphogenesis and replication using ultrastructural and molecular approaches. Virus Res. 2003;92(1):89-98.

Goldsmith CS, Ksiazek TG, Rollin PE, Comer JA, Nicholson WL, Peret TC, et al. Cell culture and electron microscopy for identifying viruses in diseases of unknown cause. Emerg Infect Dis. 2013;19(6):886-91.

Jaffe HW, Frankel SS. Kaposi's sarcoma and human herpesvirus 8. In: Horsburgh CR, Nelson AM, editors. Pathology of emerging infections. Washington, DC: ASM Press; 1997. p. 107-18.

Landry ML, Caliendo AM, Ginocchio CC, Tang Y-W, Valsamakis A. Algorithms for detection and identification of viruses. In: Jorgensen JH, Pfaller MA, Carroll KC, Funke G, Landry ML, Richter SS, et al. Manual of clinical microbiology, Vol. 2, 11th Ed. Washington, DC: ASM Press; 2015. pp. 1432-1436.

Mayer SV, Tesh RB, Vasilakis N. The emergence of arthropod-borne viral diseases: a global prospective on dengue, chikungunya and zika fevers. Acta Trop. 2016;166:155-63.

Miller SE. Electron microscopy of viral infections. In: Jerome KR, editor. Lennette's laboratory. Diagnosis of viral infections. 4th ed. Informa Healthcare: New York; 2010. p. 173-96.

Molina-Ruiz AM, Santonja C, Rütten A, Cerroni L, Kutzner H, Requena L. Immunohistochemistry in the diagnosis of cutaneous viral infections - part I. Cutaneous viral infections by herpesviruses and papillomaviruses. Am J Dermatopathol. 2015a;37 (1):1-14.

Molina-Ruiz AM, Santonja C, Rütten A, Cerroni L, Kutzner H, Requena L. Immunohistochemistry in the diagnosis of cutaneous viral infections - part II. Cutaneous viral infections by parvoviruses, poxviruses, paramyxoviridae, picornaviridae, retroviruses and filoviruses. Am J Dermatopathol. 2015b;37(2):93-106.

Peters CJ, Zaki SR. Hantavirus pulmonary syndrome. In: Horsburgh CR, Nelson AM, editors. Pathology of emerging infections. Washington, DC: ASM Press; 1997. p. 95-106.

Shibl A, Senok A, Memish Z. Infectious diseases in the Arabian Peninsula and Egypt. Clin Microbiol Infect. 2012;18(11):1068-80.

Solomon IH, Milner Jr DA. Histopathology of vaccine-preventable diseases. Histopathology. 2017;70(1):109-22.

Vasilakis N, Weaver SC. Flavivirus transmission focusing on Zika. Curr Opin Virol. 2016;22:30-5.

Zaki SR, Kilmarx PH. Ebola virus hemorrhagic fever. In: Horsburgh CR, Nelson AM, editors. Pathology of emerging infections. Washington, DC: ASM Press; 1997. p. 299-312. 